


\title{
Polisistemas anárquicos. La traducción política en el marco del polisistema
}

\author{
Gabriel Torem
}

En este texto se reflexiona sobre la capacidad de la teoría del polisistema para analizar la traducción de textos políticos. Partiendo de las definiciones de cultura y centralidad esbozadas por Even Zohar, se concluye que existe una exclusión de lo político del objeto de estudio. La hipótesis es que, al incluir en su modelo a un sujeto traductor actuante en las luchas materiales del sistema político-cultural, el polisistema, como teoría, cobra nuevo valor y aplicabilidad. En este nuevo contexto, el traductor actúa sobre el sistema receptor como tal, pero también como intelectual y militante. Una derivación obvia es que la traducción deja de pensarse como mera actividad accesoria y pasa a conformar una red de relaciones en la que traductor, militante e intelectual son facetas de un mismo sujeto, aquí definido como internacional. Se toma como ejemplo de sistema político y cultural el anarquismo de principios de siglo xx y se destaca la figura de Diego Abad de Santillán, quien, desde su actividad como dirigente, periodista, escritor y traductor, canaliza a través de su persona las relaciones entre diversos subsistemas de una especie de macrosistema internacional de los movimientos anarquistas.

PALABRAS CLAVE: traducción, política, polisistemas, anarquismo, Diego Abad de Santillán

In this paper we examine the ability of the polysystem theory to analyze the translation of political texts. Based on the definitions outlined by Even Zohar of culture and centrality concepts, it is concluded that there is a political exclusion of the subject matter. The hypothesis is that, by including in its model translator to a subject acting on the material struggles of political-cultural 
system, polysystem, as a theory, gain new value and applicability. In this new context, the translator acts on the receptor system as such, but also as an intellectual and activist. An obvious derivation is that the translation stops mere thought of as ancillary activity and passes form a network of relationships in which translator, activist and intellectual are facets of the same subject, here defined as international. Taking the example of political and cultural system the anarchism of the early twentieth century system of Diego Abad de Santillán, who from his activity as leader, journalist, writer and translator, channeled through him stands relations between various subsystems of a kind of macro system international of anarchist movements.

KEYWORDS: translation, politics, literatures, anarchism, Diego Abad de Santillán.

Fecha de recepción: 20 de septiembre de 2013

Fecha de aceptación: 12 de noviembre de 2013 
Gabriel Torem

Universidad de Buenos Aires

Facultad de Filosofía y Letras

Polisistemas anárquicos.

La traducción política en el marco del polisistema

\section{Introducción}

La traducción de textos políticos, además de proporcionar información valiosa sobre los procesos históricos de formación de determinados colectivos, es una herramienta de reflexión sobre la propia práctica y la figura del traductor. En ocasiones, la traducción es un acto militante, en el que el sujeto asume un compromiso tanto por la selección de textos fuente como por el resultado en texto meta. La definición del sujeto traductor aparece cruzada por sus otras prácticas políticas e intelectuales. Del lugar subsidiario de la visión más tradicional, según la cual el intelectual comprometido es, además, traductor, se puede pasar a pensar en un traductor comprometido o un traductor militante, o incluso como un activista cuya acción política gire en torno de la traducción. Nos referimos aquí al traductor que efectivamente hace de su práctica un compromiso con alguna causa más que a aquel traductor de oficio propuesto por Newmark ("El traductor..."), cuya acción política se restringe a las decisiones léxicas en materia sexista o de discriminación, aunque sin duda uno y otro pueden coincidir en una misma persona.

Diego Abad de Santillán, o Sinesio Baudillo García Fernández, cual fuera su verdadero nombre, fue en parte militante, en parte intelectual 
y, fundamentalmente, traductor. Desde su infancia - nació en España y de niño vino a vivir a Argentina - estuvo signado por el vínculo entre América y Europa. Su voluminosa producción intelectual, la cantidad ingente de traducciones realizadas y su praxis militante en las filas del anarquismo internacional son ejemplos de cómo la traducción puede convertirse en un instrumento de lucha del dirigente revolucionario o el intelectual comprometido. En Abad de Santillán, la traducción acompaña cada acción política y actúa como organizador del pensamiento político de las bases. Su caso, sin embargo, no es único ni excepcional, aunque sí es peculiar el hecho de que no haya quedado en el anonimato, cosa que, por otra parte se explica mucho más por su papel como cuadro y organizador de diversos movimientos obreros nacionales e internacionales y por su posición de director del periódico anarquista La protesta que por su oficio de traductor.

El estudio de la traducción desde una perspectiva política no es nuevo. Venuti, por ejemplo, en The Translator's Invisibility hace un desarrollo muy detallado sobre cómo la política influye en las formas de traducir. Tampoco es nuevo el estudio de la traducción en la historiografía. La obra de Juan Suriano (2001), Anarquistas, pasa revista a muchas de las traducciones (casi siempre de Diego Abad de Santillán) que introdujeron a los pensadores europeos y rusos en el pensamiento ácrata argentino. También abona el terreno Tarcus, con Marx en Argentina, al analizar las traducciones de fragmentos de El capital realizadas por Juan B. Justo. Sin embargo, Venuti no se ocupa de las traducciones políticas o de textos políticos en sí, y los historiadores Tarcus y Suriano hacen sus análisis desde la perspectiva historiográfica. A decir verdad, carecemos de herramientas traductológicas para pensar la traducción política, lo que no implica que no dispongamos de teorías que puedan adaptarse a nuestros fines.

La teoría del polisistema, con su premisa de estudiar los textos como hechos de la cultura receptora da el salto analítico necesario para abordar la traducción como fenómeno social. Si bien se postula claramente como una teoría que analiza la totalidad de los fenómenos sociales dentro de un sistema, no logra o, más bien, no intenta dar cuenta de las luchas materiales que determinan el desarrollo histórico y que, desde una perspectiva materialista son siempre el correlato objetivo de los hechos culturales. 
En las ciencias humanas, hay teorías con pretensiones totalizadoras y teorías específicas, aplicables a determinadas prácticas. Como se sospechará, esta distinción no es fácil de trazar: en primer lugar, las teorías son dinámicas y, en ese sentido, continuamente recortan sus objetos de estudio y buscan nuevos ámbitos de aplicación. En segundo término, lo que puede interpretarse como insuficiencia explicativa, es decir, como incapacidad para explicar algo, bien puede pensarse como una exclusión de objeto y en consecuencia como una restricción. Por esas lindes de la indeterminación merodea la teoría del polisistema. Heredera del formalismo ruso tardío, se plantea como un método para comprender las culturas desde una perspectiva integralista y dinámica. Todo lo que ocurre dentro de una cultura forma parte de un polisistema y la posición de cada elemento en éste depende de una dinámica de lucha por acceder al centro, o lugar de mayor prestigio. Even Zohar toma de Tinjanov la idea de mutación de los sistemas. Según éste, los sistemas se organizan en series, que se modifican en virtud de factores históricos. Veamos cómo resume Gentzler la visión de lo literario en una cultura según Tinjanov.

Se hacen evidentes dos cambios en el pensamiento de Tinjanov: en primer lugar, la "literariedad" deja de definirse por fuera de la historia, es decir, su existencia pasa a depender de las interrelaciones que establece; en segundo lugar, las unidades formales pierden importancia a la vez que cobran relevancia las leyes sistémicas que rigen las relaciones literarias (Contemporary Translation Theories, 111).

En cada serie, diferentes modelos, o conjuntos de repertorios, a lo largo del tiempo, pugnan por ocupar un lugar central. Lo sincrónico, la fotografía del instante, es el ordenamiento jerarquizado y dinámico de esos elementos que lograron ocupar su lugar. Evidentemente, cada elemento del sistema está condicionado por el eje diacrónico. Este interviene en la sincronía estableciendo jerarquías y convirtiendo el sistema cerrado a la Saussure en un sistema abierto, o polisistema.

La teoría del polisistema nos es especialmente cara por el lugar central que adjudica a la traducción. En efecto, si el lugar de cada elemento 
dentro del sistema surge de luchas históricas, la inserción de la traducción como hecho foráneo dentro del cuerpo de la cultura receptora merece la mayor de las atenciones. ¿Cómo llega a ingresar en el sistema? ¿Cuáles son las condiciones de posibilidad para que se traduzcan determinados textos y no otros? Gideon Toury lo plantea en los siguientes términos:

Debe recordarse que el motivo principal de este trabajo es la convicción de que no son hechos aislados ni la posición y la función de las traducciones (como entidades) o de la traducción (como actividad) en una supuesta cultura receptora, ni la forma que ha de adoptar una traducción (y por lo tanto las relaciones que la ligan al original), ni las estrategias empleadas durante su elaboración. ${ }^{1}$ (Descriptive Translation..., 24).

El esquema es sumamente útil para pensar políticas de traducción, ya sea implementadas por las instituciones o los propios agentes (el mercado, en términos de Even Zohar). También es útil para analizar métodos y estrategias de traducción históricamente situados o para pensar la recepción de la traducción como un síntoma del estado de una cultura dada. Por ejemplo, una cultura naciente o renaciente, como la cultura gallega de fines del siglo xx, se nutrirá de traducciones para constituir un corpus en lengua propia, del que carecería sin la presencia de elementos "importados".

Sin embargo, se le han achacado algunas debilidades que, de alguna manera, minan su adecuación explicativa. Bein ("La teoría del polisistema...” y “¿Quién fija la norma...”), por ejemplo, resalta el hecho de que, en las macrocomunidades lingüísticas, como las áreas de influencia del español, el portugués, o el inglés, se da cada vez con más concentración la presencia de centros editores radicados en las metrópolis que alimentan a todos los sistemas de la periferia. La teoría del polisistema debería dar cuenta de las interacciones que hacen posible que las traducciones que adopta un sistema cultural central ingresen automáticamente o no en los sistemas de la periferia, sobre todo teniendo en cuenta la insistencia de Even Zohar sobre el hecho de que los sistemas son fundamentalmente culturales y no lingüísticos. Críticas como las

\footnotetext{
${ }^{1}$ Traducción mía.
} 
de Bein señalan los vacíos explicativos del modelo, vale decir: aquellas cosas que no puede - o todavía no puede - justificar.

Ahora bien: ¿cuál es el objeto de la teoría del polisistema? ¿Queda algo fuera de ese objeto? Al principio decíamos que la teoría del polisistema se encuentra en el linde entre las teorías generales, que intentan abarcarlo todo, y las específicas. En tanto teoría de la cultura, efectivamente intenta explicar todo lo que hace al quehacer humano. Even Zohar es explícito al señalar que, por ejemplo, el sistema literario va muchísimo más allá de lo textual. Incluso, añade, puede que lo textual, bajo ciertas circunstancias, sea secundario para el sistema literario.

En dos ensayos titulados "El papel de las literaturas en la formación de las naciones europeas" y "La cultura como bienes y herramientas", Even Zohar hace una exégesis histórica del papel de los bienes culturales como factores de cohesión social y compromiso nacionalista. La cultura, en este paradigma, mantendría unida la nación y generaría sentimientos de patriotismo, tales como ir a la guerra y pelear por un pabellón. Afirma, también, que en el sistema cultural, las pujas entre centro y periferia no reflejan ni determinan de manera mecánica las relaciones sociales, aunque no especifica cuál es el mecanismo de transmisión por el que las luchas sociales se traducen en movimientos centrípetos y centrífugos dentro del polisistema. Más adelante volveremos sobre este tema, que atañe directamente a la traducción política.

Para poder establecer un diálogo entre el polisistema y la teoría política hay que contrastar dos pares de nociones entre sí. Por un lado, habría que establecer semejanzas y diferencias entre la noción de cultura que maneja el polisistema y las concepciones de ideología propias de la teoría política. ${ }^{2}$ Por otro lado, habría que pensar las nociones de centro y periferia y su relación con el concepto gramsciano de hegemonía. Sólo entonces sería posible enmarcar la traducción política en el paradigma del polisistema.

${ }^{2}$ No entraremos aquí en discusiones en torno a las nociones de ideología. Para un inventario de las concepciones de política dentro del marxismo, véase Eagleton (Ideología...); para una definición de lo ideológico, en oposición a la ideología, véase Verón (Diccionario...). 
En el artículo "Planificación de la cultura y el mercado", Even Zohar define la cultura como "un conjunto o un repertorio de opciones que organizan la interacción social" (136). Ante la pregunta de quién fija ese conjunto o repertorio, la respuesta seria: el mercado o las instituciones, o más bien ambos. En "El sistema literario", presenta al mercado (en este caso literario) como "el agregado de los factores implicados en la compraventa de productos literarios y en la promoción de tipos de consumo" y a las instituciones como "el agregado de factores implicados en el mantenimiento de la literatura como actividad socio-cultural". Mercado, instituciones, productores, consumidores, productos y repertorios formarían el todo del sistema literario. Aunque el autor no lo explicite, el esquema, que se distribuye como el tradicional esquema comunicacional de Jakobson, sería extrapolable a la cultura en general.

Me parece que el concepto clave para esta cohesión socio-cultural es el de disponibilidad. La disponibilidad es una disposición mental que empuja a la gente a actuar en un modo que, de otra manera, podría ser contrario a sus "inclinaciones naturales". Por ejemplo, ir a la guerra para ser probablemente asesinado en la lucha contra otros hombres, sería el caso extremo, muchas veces repetido a lo largo de la historia de la humanidad (Even Zohar, 370).

Surge inevitablemente la duda de por qué Even Zohar, que se empeña en dar a la cultura, o más adelante, a la cohesión sociocultural, un poder interpelador del sujeto no usa directamente el término ideología, muchísimo más desarrollado desde la sociología y la ciencia política. El hecho de que se trate de paradigmas diferentes no resuelve la cuestión, pues da lugar a la otra pregunta: ¿para qué cambiar de paradigma? ¿Para qué forzar esta traducción entre paradigmas? La otra de las "traducciones", presentar los discursos dominantes políticamente como series centrales dentro de un sistema y no como el concepto más frecuente de discursos hegemónicos, es, además de una traducción también forzada, un anacronismo.

Apelar a los formalistas rusos implica, además de una puesta en práctica de sus hipótesis sobre la presencia de Rusia en el sistema israelí, 
omitir la evolución política de los estudios literarios y culturales a partir de la época de Tinjanov y Ejxembaum, sobre todo los de Gramsci. No queremos extendermos demasiado sobre este punto, que al fin y al cabo no es el tema central de nuestro trabajo, pero diremos que mencionar a Gramsci habría implicado aceptar el valor de la lucha de clases en la construcción de hegemonías, o, en términos de Zohar, repertorios y modelos centrales. No apelar a luchas económicas de poder revela también que la teoría del polisistema está, pese a sí misma, en solución de continuidad con los formalistas más ortodoxos y su idea cientificista de la literariedad.

Aquí es donde la teoría deja el paso a los sujetos, quienes a través de su acción difunden las ideas culturales y políticas por el mundo. Estos sujetos internacionales, por así decirlo, son los clásicos reporteros, que envían crónicas a revistas de ultramar, los que cubren hechos políticos trascendentes o ejemplificadores, los que organizan fondos de huelgas internacionales, los que vinculan organizaciones de diversos países y los que, a través de la traducción, realizan cualquiera de estas tareas.

\section{Traducción y anarquía}

Podría decirse que lo que le falta a la teoría del polisistema para poder aplicarse a la traducción política es un sujeto. Insertado el sujeto, las piezas se reacomodan de otra manera, aunque tal vez menos novedosa o más trillada. El subsistema político cobra vida y se convierte en escenario de luchas; las traducciones de determinados autores dejan de ser una transferencia hecha para llenar un hueco dentro de un sistema y pasan a ser la decisión de un sujeto o un colectivo que intenta, a través de la inserción de nuevas ideas, influir sobre un grupo social y reposicionarse en la lucha política.

Admitamos que esta premisa entraña el riesgo de quitar originalidad a la teoría, acercándola a las teorías románticas e incluso exegéticas que buscan en la biografía del traductor datos pertinentes para la traducción. Pues no es tan así, ya que incorporar al sujeto no implica necesariamente renunciar a los valiosos aportes de la teoría del polisistema, en particular las prácticas de estudiar las traducciones como hechos de la 
cultura meta y de establecer vínculos entre sistemas relacionados a partir de la traducción.

Son muchos y conocidos los traductores que han ejercido alguna acción política con sus escritos. Los casos más famosos son San Jerónimo y Martín Lutero, con sendas traducciones de la Biblia. Si bien es indudable que la aparición de la Biblia primero en latín y luego en vulgata (alemán en este caso) desató modificaciones en los sistemas receptores, y que, de hecho, los sistemas del latín y de las lenguas vulgares manifestaban un vacío en cuanto a la presencia de textos religiosos, un exacerbado objetivismo teórico puede hacernos perder de vista los "escándalos" políticos que desató la importación lingüística del texto sagrado en ambos casos y la actitud contestataria de los traductores y los grupos que éstos representaban.

Aun asumiendo que el surgimiento de la imprenta es el paso decisivo para el desarrollo de una cultura escrita de masas, es solo a fines del siglo XIX y comienzos del siglo XX cuando puede hablarse cabalmente de una relación generalizada entre la escritura y las masas. Los teóricos de los movimientos obreros, tanto socialistas como anarquistas, comprendieron este fenómeno e hicieron mucho hincapié en la existencia de periódicos proletarios y en la difusión de las ideas mediante colecciones de obras teóricas. Es esta una etapa en la que la traducción política asume un papel fundamental, porque, además, conjuga estos fenómenos con la pregonada internacionalización de la lucha de clases.

Volvamos a los libertarios de estas pampas. En tanto lo permitió la libertad de prensa, las publicaciones anarquistas se multiplicaron a partir de 1870 y hasta 1901, que es el año en que el gobierno argentino empieza a percibir la amenaza de la ebullición del movimiento obrero (Suriano, Anarquistas..., 183). Recordemos que las publicaciones anarquistas, y la prensa política en general, son mucho más que subsistemas de una cultura: la prensa en manos de las organizaciones revolucionarias es, cómo explicaría años más tarde Lenin, una herramienta de formación de cuadros y cohesión política:

A menos que formemos células políticas fuertes en cada localidad, no nos serviría de nada ni siquiera el mejor de los periódicos de tirada nacional, para toda Rusia. Esto no se discute. Sin embargo, el punto central 
es que no hay manera de formar células políticas fuertes si no es a través de un periódico nacional, que llegue a toda Rusia (What to Do?, 100). ${ }^{3}$

En la Argentina de principios del siglo xx, las publicaciones anarquistas son, entonces, una herramienta de la organización y, además, un subsistema cultural. Esto hace de sus sujetos más que meros productores para un mercado; los torna en intelectuales comprometidos con una causa política. Lo que, además, se comprueba en el hecho de que, de no ser por sus prácticas disruptivas, como subsistema cultural, el pensamiento anarquista finisecular habría tenido el camino a la centralidad bastante allanado, toda vez que sus ideas no representaban lo radicalmente distinto. En palabras de Suriano, "si el anarquismo no parece haber constituido un movimiento contracultural en tanto su mensaje se hallaba penetrado de elementos provenientes de otras vertientes doctrinales, sus prácticas políticas eran indudablemente más subversivas de los valores corrientes" (Anarquistas..., 28). Por eso, el estudio de los "productores" es inescindible de su praxis política.

Si hay algo que define al anarquismo argentino es la extranjeridad. La ley de Residencia de 1902, que en su artículo $2^{\circ}$ dice: "El Poder Ejecutivo podrá ordenar la salida de todo extranjero cuya conducta comprometa la seguridad nacional o perturbe el orden público", iguala extranjeridad con agitación social y abre la puerta a las grandes represiones que sufrirá el movimiento anarquista en las dos primeras décadas del siglo xx. Esta equiparación anarquismo-extranjería no es forzosa ni automática, sino culturalmente construida: los inmigrantes europeos que empezaron a llegar a partir de la década de 1870 ocuparon todos los ámbitos de la vida argentina. Se nuclearon en colonias rurales, se hicieron comerciantes, muchos fueron obreros y, muchos de ellos, sí, fueron anarquistas.

Lo que determina la identificación del extranjero con el ácrata es que el sistema cultural anarquista es importado, así sea en traducción o en lengua original. Desde los sectores conservadores, se ha hecho muchísimo hincapié en el hecho de que las ideas anarquistas eran foráneas. Y con razón. Como sistema joven y primario — en el sentido de dinámico,

\footnotetext{
${ }^{3}$ Cursivas orginales. La traducción es mía.
} 
que le da Even Zohar - la cultura anarquista argentina se nutrió de los textos de Kropotkin, Bakhunin, Malatesta, Quiroule y otros teóricos del anarquismo, que llegaban a veces en lengua original, a veces en español, traducidos en España, y a veces se traducían en Argentina. La questione sociale, dirigida por Malatesta, y L'avvenire, fueron dos de las publicaciones que llegaban directamente en italiano. Incluso La Protesta, la publicación anarquista de mayor trayectoria (que se sigue editando hasta el día de hoy), entre 1907 y 1908 editó una columna diaria en italiano escrita directamente en Argentina (Suriano, Anarquistas..., 28).

Tomemos el caso de la revista Ideas y figuras. Como se plantea en su primer número, su objetivo es difundir la cultura entre la clase trabajadora argentina y forjar una conciencia de lucha. No nos extenderemos sobre esta publicación, pero su carácter también busca modelar al proletariado argentino según un molde moral propio del Iluminismo, del que el anarquismo decimonónico es sin dudas tributario. Para el público lector de la Argentina, mayormente inmigrante, hablante de otras lenguas o con un conocimiento incipiente del español, existe un gran vacío en el mercado de la literatura política doctrinaria. Ése es el vacío que viene a llenar la prensa anarquista, y lo llena tanto con contenidos propios, gestados en las luchas culturales y políticas nacionales, como con contenidos surgidos en los sistemas centrales; en este caso, en España.

Esta idea, en política, no nos es nueva. El marxismo, con su teoría de la revolución internacional la vio claramente. La plantea el propio Marx, con su ley del desarrollo desigual y combinado. En La revolución permanente (1929), Trotsky la amplía, explicando que la clase obrera mundial, en su dialéctica histórica, nunca saltea etapas, aunque, respetando esta regla de oro, cada clase obrera en su estado-nación, sí pueden hacerlo. Es la justificación del hecho de que la revolución socialista se haya dado en Rusia antes que en Alemania, pero también puede entenderse como un corolario de la afirmación de que los vínculos culturales entre diferentes países, entre otras cosas a través de la traducción, pueden vehiculizar las luchas políticas, dando al desarrollo político y cultural un carácter mundial.

Volvamos a Ideas y figuras. Escriben allí las figuras más salientes del anarquismo y el socialismo español como Pi y Margall y Joaquín Belda. Además, se importan problemáticas desarrolladas en la península. Por 
ejemplo, el modelo de educación anarquista, el desarrollado en la Escuela Moderna, de Francisco Ferrer, directamente se importa de España y se implanta en Argentina con un relativo éxito. Sin duda, la propaganda desarrollada en el número 25 de la revista, de febrero de 1910, fue un gran motor para el desarrollo de escuelas ferrerianas en la Argentina. Entre los años 1910 y 1911, la revista incluye directamente una sección titulada "Traducciones", en la que se incluyen poemas fundamentalmente traducidos del francés, que sin duda, vienen a conformar lo que la revista, seguramente en un todo de acuerdo con la opinión de su director Alberto Ghiraldo, considera es la formación cultural que deben tener las masas oprimidas nacionales.

\section{Diego Abad de Santillán: el traductor del anarquismo}

La figura de Diego Abad de Santillán es esencial para poner en valor el lugar del sujeto como vaso comunicador de la dialéctica política de diferentes naciones. Sus migraciones entre Europa y Argentina lo determinan como puente no entre culturas sino entre desarrollos sociales.

La crisis española de principios de siglo xx fuerza a muchas familias de labriegos a emigrar, muchas de las cuales llegan a América. Hijo de una de esas familias es Abad de Santillán. Cuando, de joven, regresa a España a completar sus estudios de medicina, se interesa por la militancia política y, luego de una campaña de agitación en contra de la figura monárquica de Alfonso XIII, cae detenido. Allí traba amistad con detenidos libertarios y es su calidad humana, más que ninguna otra consideración política, lo que sella su vínculo con el anarquismo que lo acompañará el resto de su vida.

Muchas veces, el traductor se posiciona en el lugar de quien colabora desde afuera. Esta situación no debe considerarse desde un punto de vista especulativo o ahistórico, sino que debe entenderse con toda la fuerza de las circunstancias históricas.

Para nuestro análisis, no importa tanto buscar qué factor psicológico lleva al sujeto a elegir el compromiso con lo extranjero o lo físicamente inaccesible. Se trata de apreciar el valor político que puede tener la colaboración internacional en situaciones en las que la denuncia interna está 
sujeta a la censura o la represión. Ante el fusilamiento del educador Francisco Ferrer por parte del franquismo, la única denuncia viable, incluso a sabiendas de que los anarquistas argentinos tampoco tenían muchas garantías en cuanto a su libertad o su integridad física, es la internacional, y es Abad de Santillán quien la encabeza en Rosario.

De alguna manera, la militancia internacional está históricamente determinada. Esa determinación es la que fija los vínculos entre los sistemas políticos. En Buenos Aires, nuestro personaje funda la revista $L a$ España futura. A nivel cultural, la revista nutre el sistema de la literatura política con ideas europeas; a nivel político, fomenta, nada menos, el desarrollo de la fuerza social que protagonizó las luchas obreras desde fines del siglo XVIII hasta el advenimiento del Peronismo.

Entre 1922 y 1926 Diego Abad de Santillán viaja a Berlín. Este período, tan rico en producción literaria, traducciones y militancia internacional, está muy bien historizado por María Fernanda de la Rosa (“Diego Abad de Santillán..."). Es una época de lucha ideológica en el seno de las organizaciones obreras en el que los anarquistas buscan que la Internacional Roja no coopte sus luchas. En ese contexto, en 1919, se funda en Berlín la Asociación Internacional de los Trabajadores, cuyo objetivo principal era nuclear la lucha proletaria mundial allí donde Marx y los luxemburguistas habían anunciado que se daría la primera revolución socialista. Allí se despliega de lleno el rol del traductor como comunicador de luchas sociales.

Diego Abad de Santillán representa a las organizaciones de Uruguay, Chile, México, Perú, Paraguay, Brasil y Argentina-a través de la Federación Obrera Regional Argentina - con el mandato de defender las organizaciones independientes de los trabajadores y la no conciliación con la Unión Soviética. No es un lugar retórico o meramente teórico porque la postura del emisario traduce luchas internas que se daban en el interior de cada organización. Como encargado de prensa y finanzas de la Asociación Interncional de los Trabajadores, Santillán estipula que cada entidad adherente aporte una cotizacíón fija, lo que garantiza un vínculo material y no sólo declamativo entre los trabajadores de todo el mundo.

A la par de su papel político, Abad de Santillán despliega su actividad como traductor en el campo editorial. El papel del traductor aquí se con- 
funde con el del militante y el del intelectual. Escribió para un sinnúmero de publicaciones, como los periódicos españoles Iberión y Liberión y la Revista Internacional Anarquista. Simultáneamente, dedicaba preciosas horas a la traducción de cuanto material cayera en sus manos y considerara útil para el desarrollo intelectual y organizativo del proletariado. Así es que Diego Abad de Santillán tradujo no solo obras políticas, en su inmensa mayoría de prestigiosos autores libertarios, sino también escritos sociológicos o filosóficos y tratados de medicina, en especial aquellos relacionados con la influencia del trabajo sobre el cuerpo humano.

En una carta del 24 de setiembre del año 1922, el administrador del periódico La Protesta, Apolinario Barrera, le escribe quejumbroso pidiéndole que deje de dedicar tantas energías a la traducción y se dedique a tareas "más útiles", como un proyectado "programa cultural" en Alemania.

\begin{abstract}
Al irse de acá pensaba usted huir de la mecanización de La Protesta y de la inútil repetición a que lo condenaba la propaganda. Pero ahora, por lo visto, ha caído nuevamente en la mecanización que supone el exceso de trabajo y su afán de llenar las columnas de La Protesta [...] [E]s de lamentar que no pueda usted realizar en Alemania el programa cultural que se había trazado [...] [L]e diré más aún: no me parece muy superior el servicio que usted puede prestar al movimiento de ideas apartándose de ese rudo bregar cotidiano, que es el periodismo, y dedicándose lo más posible a serios estudios que lo han ocupado en una mole de traducciones de menor cuantía que terminarán por agotarlo e inutilizarlo para todo esfuerzo superior (De la Rosa, "Diego Abad de Santillán..." 195-196).
\end{abstract}

Ciertamente, Santillán es un traductor apasionado. En él la traducción no es un accesorio de la teoría política, y por allí seguramente pasa la queja de quienes no ven el potencial de la traducción en la creación de sistemas de pensamiento novedosos para las culturas nacientes o en formación. Las traducciones de Diego Abad de Santillán se publican en tres editoriales diferentes: Argonauta, Minerva y Liga. La primera y la tercera publican textos doctrinarios. Minerva, en cambio, es una editorial volcada a la publicación de textos sociológicos o de interés general. Las tres están dirigidas por líderes del movimiento libertario argentino. 
El propósito es tener un campo de salida para novedades que no concuerdan con el carácter libertario de Argonauta; las publicaciones de esta editorial son escritos doctrinarios del comunismo anárquico. La idea es que Minerva permanezca al margen de esta situación ideológica y edite obras tanto de orden científico como social o filosófico. "Tiene usted allí abierta la puerta para traducir cualquier escrito interesante", le propone Barrera. Su participación en los proyectos de las dos editoriales es constante (De la Rosa, "Diego Abad de Santillán..." 195-196).

Lo que completa el cuadro de Abad de Santillán como figura polisistémica, si se nos permite la expresión, es que encara estos proyectos desde Europa. Es, a la vez, una prueba más de que el sujeto no es una mera pieza de ajedrez, en tanto y en cuanto es Abad de Santillán, situado fuera de la cultura argentina receptora, quien tiene el poder de elegir a discreción cuáles son los autores y textos que traducirá o que incluirá en las colecciones. Como estratega político e intelectual, también percibe con agudeza lo que hoy llamaríamos el centro y la periferia del sistema de la cultura libertaria hispanófona y, dando una vuelta de tuerca más a lo que Guideon Touri (Descriptive Translation...,129 y ss.) llama "traducción indirecta", propone editar en París o Barcelona el libro que ha de escribir con López Arango sobre la historia del movimiento obrero internacional y cuyo público destinatario propuesto es el argentino. No hay transcodificación lingüística: simplemente hay una traducción de espacios simbólicos: del sistema alemán, donde el texto castellano es extranjero, al sistema barcelonés, donde ya no es extranjero, pero quizás sí sea marginal, al sistema argentino o latinoamericano, donde la traducción asume el rol central que toca a todo lo llegado de Europa. Vale decir, además, que la circulación de esos textos traducidos en Europa por casi toda América Latina, sumado al hecho de que muchos otros libros teóricos llegaban efectivamente traducidos desde España abona la idea de que el anarquismo peninsular y americano forman un mismo sistema, con las subdivisiones correspondientes, en el que la parte argentina y la española peleaban por ocupar el centro y los demás países americanos tenían posiciones más cabalmente marginales. 


\section{Conclusiones}

Hemos visto a lo largo de estas páginas cómo la teoría del polisistema excluye de su objeto la traducción como hecho político. Vimos también que efectivamente podría incluirla, con la condición de incorporar una noción fuerte de sujeto. La presencia del sujeto de ninguna manera sería un regreso a teorías exegéticas o románticas, toda vez que se mantienen los demás postulados básicos del polisistema: análisis de las traducciones como hechos de la cultura meta y como elementos de sistemas dinámicos. Se han mencionado brevemente algunos de los aspectos más salientes de la trayectoria de Diego Abad de Santillán, quien ha servido como ejemplo de traductor, intelectual y activista comprometido. La figura de Santillán, además, nos ha permitido valorar el papel político del traductor, poniéndolo a la misma altura que el del intelectual o el del cuadro dirigente. Por último, valiéndonos de la actividad editorial de Santillán en Europa, hemos podido configurar un sujeto traductor vinculado a lo internacional y que motoriza nuevos tipos de vínculos entre subsistemas emparentados, como los de las organizaciones anarquistas latinoamericanas y europeas, cuya confluencia constituiría el sistema de la cultura libertaria hispanófona.

\section{REFERENCIAS}

BeIn, Roberto, "La teoría del polisistema hoy: elementos vigentes y aspectos a revisar", en Actas del III Congreso Latinoamericano de Traducción e Interpretación, Buenos Aires, Colegio de Traductores Públicos de Buenos Aires, 2000.

BeIn, Roberto, “¿Quién fija la norma en las traducciones?”, en Políticas lingüísticas: normas e identidad. Estudios de casos y aspectos teóricos en torno al gallego, el español y lenguas minoritarias, Roberto Bein y Joachim Born (eds.), Buenos Aires, UBA-FFyL, 2001.

Eagleton, Terry, Ideología. Una introducción, Buenos Aires, Paidós, 1997.

Even-Zohar, Itamar, "Planificación de la cultura y el mercado", en Polisistemas de cultura, <http://www.tau.ac.il/ itamarez/works/papers/trabajos/ polisistemas_de_cultura.htm $>$ [08/10/2012].

Even-Zohar, Itamar, "La Función de la literatura en la creación de las naciones de Europa". en Avances en Teoría de la literatura: Estética de la Recepción, 
Pragmática, Teoría Empírica y Teoría de los Polisistemas, Dario Villanueva (ed.), Santiago de Compostela, Universidade de Santiago de Compostela, 1994b, 357-377.

Gentzler, Edwin, Contemporary Translation Theories, Clevedon, England, Multilingual Matters Ltd, 2001.

Lenin, What to Do? [1902], en Selected Works, vol. 1, trad. al inglés Joe Fineberg and George Hanna, Moscow, Foreign Languages Publishing House, 1961, 119-271.

Newmark, Peter, "El traductor, ciudadano del mundo" (entrevista de Miguel Wald), Revista Idiomanía, núm. 30, octubre de 1994.

Revista Ideas y Figuras (1909-1911), números 17 a 42. Buenos Aires/Montevideo

Rosa, María Fernanda de la, "Diego Abad de Santillán y su actuación en el anarquismo argentino", Temas de historia argentina y americana, núm. 1, julio-diciembre de 2002.

Suriano, Juan, Anarquistas, cultura política y libertartia en Buenos Aires, 1890-1910, Buenos Aires, Manantial, 2001.

TARCus, Horacio, Marx en Argentina, sus primeros lectores obreros, intelectuales y científicos. Buenos Aires, Siglo XXI, 2009.

Toury, Gideon, Descriptive Translation Studies and Beyond, Filadelfia, John Benjamins Publishing Co., 1995.

Verón, Aníbal, Diccionario de lugares no comunes, Barcelona, Gedisa, 2004. 